\title{
Yoğun bakım hemşirelerinin ekip çalışması tutumlarının incelenmesi
}

\section{Investigation of teamwork attitude of intensive care nurses}

\author{
(ㄷ) Fatma Düzgün, ${ }^{1}$ () Derya Uzelli Yılmaz, ${ }^{2}$ (D) Dilek Karaman, ${ }^{3}$ () Hava Gökdere Çinar, ${ }^{4}$ \\ (1) Yurdanur Dikmen, ${ }^{5}$ (i) Dilek Yılmaz \\ 'Bursa Uludağ Üniversitesi Hastanesi, Bursa, Turkey \\ ${ }^{2}$ İzmir Katip Çelebi Üniversitesi, Sağlık Bilimleri Fakültesi, Hemşirelik Bölümü, İzmir, Turkey \\ ${ }^{3}$ Bülent Ecevit Üniversitesi, Sağlık Hizmetleri Meslek Yüksek Okulu, Yaşıı Bakımı Programı, Zonguldak, Turkey \\ ${ }^{4}$ Bursa Uludağ Üniversitesi, Sağlık Bilimleri Fakültesi, Hemşirelik Bölümü, Bursa, Turkey \\ ${ }^{5}$ Sakarya Üniversitesi, Sağlık Bilimleri Fakültesi, Hemşirelik Bölümü, Sakarya, Turkey \\ ${ }^{6}$ Bursa Uludağ Üniversitesi, Sağlık Bilimleri Fakültesi, Hemşirelik Bölümü, Bursa, Turkey
}

\section{Özet}

Amaç: Bu araştırmanın amacı, yoğun bakım hemşirelerinin ekip çaIışması tutumlarının incelenmesidir.

Gereç ve Yöntem: Araştırma, bir üniversite hastanesinin yoğun bakım ünitelerinde yürütülmüştür. Araştırmanın örneklemini, araştırmanın yapıldığı tarihlerde izinli ve raporlu olmayan ve araştırmaya katılmayı kabul eden 88 hemşire oluşturmuştur. Araştırmanın verileri; "Hemşire Tanıtım Formu” ve "Ekip Çalışması Tutumları Ölçeği (EÇTÖ)" ile toplanmıştır. Araştırma verilerinin analizinde; sayı, yüzde, ortalama ile Bağımsız T testi, ANOVA testi ve Pearson Korelasyon Analizi kullanılmıştır.

Bulgular: Araştırmaya katılan hemşirelerin yaş ortalaması $31.01 \pm 5.88$ (min: 22, max: 53) yıl, \%75'inin kadın, \%90.9'unun lisans mezunu, \%35.2'sinin anestezi ve reanimasyon yoğun bakım ünitesinde çalıştığı bulunmuştur. Hemşirelerin EÇTÖ toplam puan ortalaması $110.05 \pm 10.08$, alt boyut puan ortalamalarından; ekip yapısı 23.20 \pm 3.25 , karşılıklı destek $16.94 \pm 2.71$, iletişim 20.63 \pm 2.29 , liderlik $25.10 \pm 3.05$, durum izlemi $24.17 \pm 2.40$ olarak saptanmıştır. Hemşirelerin eğitim durumları ile EÇTÖ toplam puan ortalamaları arasında istatistiksel olarak anlamlı bir fark bulunmuştur. Diğer yandan, hemşirelerin cinsiyet, medeni durum, günlük bakılan hasta sayısı, mesleki derneğe üyelik ve ekip çalışmasına yönelik bir eğitim alma durumları ile EÇTÖ toplam puan ortalaması ve ölçek alt boyut puan ortalamaları arasında istatistiksel olarak anlamlı bir fark saptanmamıştır.

Sonuç: Bu araştırma sonucunda; yoğun bakım hemşirelerinin ekip çalışması tutumlarının orta düzeyde olduğu bulunmuştur.

Anahtar Sözcükler: Ekip çalışması tutumu; hemşirelik; yoğun bakım hemşiresi.

\begin{abstract}
Introduction: This study was conducted to examine the teamwork attitudes of the intensive care nurses.

Methods: This study was conducted in intensive care units of a university hospital. The sample of the study consisted of 88 nurses who were not on sick leave and accepted to participate in the study. The data of the study were collected with the "Nurse Introductory Form" and "Teamwork Attitudes Scale (TAS)". Number, percentage, mean, independent T test, ANOVA test and Pearson Correlation Analysis were used to analyse the study data.
\end{abstract}

Results: The mean age of the nurses participating in the study was found to be $31.01 \pm 5.88$ (min: 22, max: 53 ), $75 \%$ of them were female, $90.9 \%$ had university graduate, $35.2 \%$ were employed in the anaesthesia and reanimation intensive care unit. As a result of the statistical analysis, the total mean TAS score of the nurses was found as $110.05 \pm 10.08$, from the subscale mean scores; team structure was $23.20 \pm 3.25$, mutual support was $16.94 \pm 2.71$, communication was $20.63 \pm 2.29$, leadership was $25.10 \pm 3.05$, and condition monitoring was found as $24.17 \pm 2.40$. There was a statistically significant difference between the educational status of nurses and the total score of TAS. On the other hand, no statistically significant difference was found between the gender, marital status, number of daily care of the nurses, the number of patients receiving education and team work, and the mean score of the TAS total mean score and the scale subscale mean scores.

Discussion and Conclusion: As a result of this study, it was found that the attitudes of the intensive care nurses were moderate.

Keywords: Teamwork attitude; nursing; intensive care nurse.

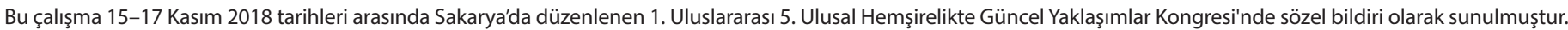

Corresponding (İletişim): Dilek Yılmaz, Bursa Uludağ Üniversitesi, Sağlık Bilimleri Fakültesi, Hemşirelik Bölümü, Bursa, Turkey E-mail (E-posta): dilekkara15@hotmail.com

Received (Geliş Tarihi): 20.11.2018 Accepted (Kabul Tarihi): 14.03.2019 
G ünümüzde sağlık bakım kurumlarında işleyiş mekanizmalarının en önemli bölümü; çalışma grupları, komiteler ya da ekipler tarafından birlikte hareket edilerek yürütülmektedir. ${ }^{[1,2]} \mathrm{Bu}$ oluşumlar içerisinde diğerlerine nazaran ekipler daha hızlı organize olabilme, odaklanabilme, eyleme geçebilmekte, yüksek başarı göstererek değişime ayak uydurabilmektedir. ${ }^{[2]}$ Ekip, belli bir hedef çerçevesinde sürdürülebilir bir etkileşim ve yardımlaşmanın gerekli olduğu, iki veya daha fazla üyeden oluşan kişiler topluluğudur. ${ }^{[3]}$ Ekip, üyeleri arasında karşılıklı saygı ve güven çerçevesinde, ortak amaçlar doğrultusunda her üyenin bilgi, beceri ve bakış açısından faydalanııır. ${ }^{[4]}$ Ekip üyelerinin her biri kendi uzmanlık alanları doğrultusunda hizmet sunar. ${ }^{[5,6]}$

Ekip çalışması ise örgütlerde sorunların çözümünde yararlanılan önemli bir yönetim yaklaşımı olarak ele alınmaktadır. Ekip çalışması kurumlarda iletişimin ve bilgi paylaşımının gelişmesine, ekip üyelerinin işin planlanması ve yürütülmesi sürecine katkıda bulunarak yönetime destek vermelerine olanak sağlamaktadır. Bu durum örgütlerin gelişim, yenilikçilik ve yaratıcılık boyutu için ihtiyaç duydukları enerjinin ve sinerjinin elde edilmesini sağlamaktadır. ${ }^{[2,7,8]}$

Uluslararası Çalışma Örgütünün (ILO) işyerlerinde ana stresörler olarak belirlediği unsurlar; yöneticilerle çatışmalar, rol karışıklıkları ve belirsizlik, ağır iş yükü olan hastalarla çalışma nedeniyle duygusal stres, yoğun bakıma ihtiyaç duyan ve ölme olasılığı olan hastalarla çalışma, çatışmalar ve vardiyalı olarak çalışmaktır. ${ }^{[9,10]}$ Bu unsurları göz önünde bulundurduğumuzda sağlık ekibi içerisinde en hızlı organize olabilme becerisine sahip olunması gereken ünitelerden birisi yoğun bakımlar olarak karşımıza çıkmaktadır. ${ }^{[11]}$ Yoğun bakım ünitesinde izlenen kritik hastalarda takip ve tedavi amacıyla yapılan monitörizasyon, ilaç uygulamaları ve girişimler oldukça fazladır. ${ }^{[12-14]}$ Yoğun bakım üniteleri; yüksek teknolojik araçlar donanımına sahip, riskli hasta grubunun bakım sürecinden sorumlu, sürekli izlem ve gözlem gerektiren multidisipliner ekiple hizmet sunulan özel birimlerdir. ${ }^{[1]]}$ Bu nedenle yoğun bakım ekibi arasındaki işbirliğinin kalitesi, hastaların refahı için çok önemlidir. ${ }^{[15]}$ Ekip çalışması sayesinde hasta bakımında süreklilik sağlanarak gereksiz tekrarlardan kaçınılmakta, hastaların hastanede kalış süreleri kısalmakta, zaman ve finansal kazanç sağlanmakta böylece hasta çıktıları olumlu etkilenmektedir. Ayrıca çalışanların diğer ekip üyelerinin görev tanımlarını daha iyi anladıkları, problem çözme becerilerinin arttığı dolayısıyla çalışanların iş doyumuna ve performansına olumlu yansıdığı da vurgulanmaktadıı ${ }^{[16-18]}$

Yoğun bakım ünitelerinde hasta bakım çıktılarının iyileştirilmesinde önemli bir yere sahip olan hemşireler, yoğun bakım kalitesini nitelik ve nicelik olarak oldukça fazla etkileyen ekip üyeleridir. İyileşme sürecinin hızlandırılmasında hastalarla kesintisiz 24 saat zaman geçiren yoğun bakım ünitesi hemşirelerinin çok önemli rolleri bulunmaktadır. ${ }^{[19]}$ Birçok hasta bakım hizmeti yoğun bakım hemşireleri tarafından yürütülmekte ve sunulan hemşirelik hizmeti sağ kalımı doğrudan etkileyebilmektedir. ${ }^{[12]}$ Dolayısıyla yoğun bakım biriminde çalışan hemşirelerin ekip ruhu içerisinde çalışma yeteneğine sahip olmaları önemlidir.
Konuyla ilgili literatür incelendiğinde, ülkemizde yoğun bakım hemşirelerinde ekip çalışması tutumlarını incelemeye dayalı çalışma sayısının çok sınırlı olduğu görülmüştür. Hemşirelerin etkin ve verimli çalışması sağlık kurumlarının gelişiminde ve kaliteli hizmet sunumunda oldukça büyük bir rol oynamaktadır. Bu nedenle hemşirelerin etkinlik ve verimliliğin artırılmasında önemli olan ekip çalışması tutumlarının incelenmesinin ve bunu etkileyen farklı değişkenlerin belirlenmesinin iş doyumu ve motivasyon açısından önemli olduğu düşünülmektedir. Bu araştırmanın amacı yoğun bakım ünitelerinde çalışan hemşirelerin ekip çalışması tutumlarının belirlenmesidir.

\section{Gereç ve Yöntem}

Bu araştırma tanımlayıcı ve kesitsel bir çalışmadır. Araştırma, Eylül 2018-Kasım 2018 tarihleri arasında bir üniversite hastanesinin yoğun bakım ünitelerinde çalışan hemşirelerle yürütülmüştür. Araştırmanın evrenini, bu ünitelerde çalışan 169 hemşire oluşturmuştur. Araştırmanın örneklemini ise araştırmanın yapıldığı tarihlerde izinli ve raporlu olmayan ve araştırmaya katılmaya istekli 88 hemşire oluşturmuştur (Katılım yüzdesi; 52.07).

Araştırmanın verileri; "Hemşire Tanıtım Formu” ve "Ekip Çalışması Tutumları Ölçeği (EÇTÖ)" ile toplanmıştır. Hemşire Tanıtım Formu; bu form araştırmacılar tarafından hazırlanmış olup, hemşirelerin yaş, cinsiyet, çalıştıkları yoğun bakım birimi, çalıştıkları süre, haftalık çalışma saatleri, günlük bakım verilen hasta sayısı, herhangi bir mesleki derneğe üyelik durumu ve ekip çalışmasına yönelik daha önce bir eğitim alıp almadığına ilişkin soruları kapsamaktadır. Ekip Çalışması Tutumları Ölçeği (EÇTÖ) ise bireylerin ekip çalışması konusundaki tutumlarını belirlemek üzere, Baker ve arkadaşları (2008) tarafından geliştirilmiş. ${ }^{[20]}$ ve Yardımcı ve arkadaşları (2012) tarafından Türkçe geçerlik ve güvenirlik çalışması yapılmıştır. ${ }^{[16]}$ Ölçekte yer alan ifadeler 5 'li likert özelliktedir. Bu ölçekte; Ekip Yapısı (6 soru), Liderlik (6 soru), Durum İzlemi (6 soru), Karşlıklı Destek (5 soru), Illetişim ( 5 soru) olmak üzere 5 alt boyut yer almaktadır. "Ekip Çalışması Tutumları Ölçeği'nden en az 28, en fazla 140 puan alınabilmektedir. Ölçek puanının yükselmesi hemşirelerin ekip çalışması özelliklerine yönelik tutumlarının arttığını göstermektedir. ${ }^{[16]}$

Araştırmanın yürütülmesi için öncelikle ölçeği geliştiren ve Türkçe geçerlik ve güvenirlik çalışmasını yazarlardan e-mail yoluyla yazııı izin alınmıştır. Ayrıca çalışmanın yapıldığı üniversite etik kurulundan (Karar no: 2018-15/25), araştırmanın yapıldığı kurumdan ve hemşirelerden gerekli yasal izinler alınmıştır.

Araştırmacı tarafından hemşirelere anket formları dağıtılarak, soruları yanıtlamaları istenmiştir. Anketlerin doldurulduğu sürenin hemşirelerin mesai saatlerini etkilememesine dikkat edilmiştir. Yanıtlamaları için istenen süre en fazla 30 dakika olarak hesaplanmıştır. Araştırma verilerinin değerlendirilmesi SPSS (Statistical Package For Social Science) 22.0 paket programı kullanılarak yapılmıştır. Verilerin değerlendirilmesinde, kategorik veriler için frekans ve yüzdelikler, nicel veriler için 


\section{Tablo 1. Hemşirelerin tanıtıcı özellikleri ( $\mathbf{n = 8 8})$}

\begin{tabular}{|c|c|c|}
\hline Özellikler & Sayı (n) & Yüzde (\%) \\
\hline Yaş: & \multicolumn{2}{|c|}{$31.01 \pm 5.88$} \\
\hline \multicolumn{3}{|l|}{ Cinsiyet } \\
\hline Kadın & 66 & 75.0 \\
\hline Erkek & 22 & 25.0 \\
\hline \multicolumn{3}{|l|}{ Medeni durum } \\
\hline Evli & 53 & 60.2 \\
\hline Bekar & 35 & 39.8 \\
\hline \multicolumn{3}{|l|}{ Eğitim durumu } \\
\hline Lisans & 80 & 90.9 \\
\hline Lisansüstü & 8 & 9.1 \\
\hline Çalışma yılı & \multicolumn{2}{|c|}{ Ort: $6.56 \pm 5.92$} \\
\hline \multicolumn{3}{|c|}{ Çalışılan yoğun bakım kliniği } \\
\hline Beyin cerrahi & 6 & 6.8 \\
\hline Kalp damar & 12 & 13.6 \\
\hline Koroner & 10 & 11.4 \\
\hline Genel cerrahi & 14 & 15.9 \\
\hline Anestezi & 31 & 39.8 \\
\hline Çocuk & 7 & 8.0 \\
\hline Yenidoğan & 15 & 9.1 \\
\hline \multicolumn{3}{|c|}{ Günük bakım verilen hasta sayısı } \\
\hline $1-4$ & 67 & 76.1 \\
\hline $5-10$ & 21 & 23.9 \\
\hline \multicolumn{3}{|c|}{ Hizmet içi eğitime katılma durumu } \\
\hline Evet & 63 & 71.6 \\
\hline Hayır & 25 & 23.9 \\
\hline \multicolumn{3}{|c|}{ Mesleki bir derneğe üye olma durumu } \\
\hline Evet & 57 & 64.8 \\
\hline Hayır & 31 & 35.2 \\
\hline Toplam & 88 & 100.0 \\
\hline
\end{tabular}

ortalama ve standart sapma kullanılmıştır. Ölçek puanlarının normal dağılma uygunluğunu belirlemek için verilere normallik testi uygulanmış ve normal dağııım gösterdiği için sayısal verilerin analizinde parametrik testlerden Bağımsız $T$ testi, ANOVA testi ve Pearson Korelasyon Analizi kullanılmıştır.

\section{Bulgular}

Araştırmaya katılan hemşirelerin yaş ortalamasının $31.01 \pm 5.88$ (min: 22, max: 53) yıl, \%75'inin kadın, \%90.9'unun lisans mezunu, \%35.2'sinin anestezi ve reanimasyon yoğun bakım ünitesinde çalıştığı bulunmuştur. Hemşirelerin meslekte çalışma sürelerinin $6.56 \pm 5.92 \mathrm{yıl}$, haftalık çalışma sürelerinin $43.69 \pm 3.08$ saat olduğu, \%76.1'inin günlük ortalama 1-4 hastaya bakım verdiği, \%64.8'inin herhangi bir mesleki derneğe üye olduğu ve \%71.6'sının ekip çalışmasına yönelik bir eğitim aldığı belirlenmiştir (Tablo 1).

Bu araştırma sonucunda; hemşirelerin EÇTÖ toplam puan ortalaması $110.05 \pm 10.08$, alt boyut puan ortalamalarından; ekip yapısı $23.20 \pm 3.25$, karşılıklı destek $16.94 \pm 2.71$, iletişim
Tablo 2. Hemşirelerin EÇTÖ ve alt boyutları puan ortalamaları ( $\mathrm{n}=\mathbf{8 8})$

\section{EÇTÖ ve alt boyutları}

Puan ortalamaları Ort. \pm SS

$\begin{array}{lc}\text { Ekip yapısı } & 23.20 \pm 3.25 \\ \text { Karşılıklı destek } & 16.94 \pm 2.71 \\ \text { Illetişim } & 20.63 \pm 2.29 \\ \text { Liderlik } & 25.10 \pm 3.05 \\ \text { Durum izlemi } & 24.17 \pm 2.40 \\ \text { Toplam EÇTÖ } & 110.05 \pm 10.08\end{array}$

Ort.: Ortalama; SS: Standart sapma.

$20.63 \pm 2.29$, liderlik $25.10 \pm 3.05$, durum izlemi $24.17 \pm 2.40$ olarak bulunmuştur (Tablo 2 ).

Araştırmaya dahil olan hemşirelerin meslekte çalışma süresi ile liderlik alt boyutu, haftalık çalışma saati ile EÇTÖ toplam puan ortalaması arasında istatistiksel açıdan anlamlı bir ilişki belirlenmiştir (sırasıyla; $r=0.220, p=0.039 ; r=0.255, p=0.017$ ). Buna göre, hemşirelerin meslekte çalışma süresi arttıkça liderlik tutumlarının arttığı görülmektedir. Ayrıca; hemşirelerin eğitim durumları ile EÇTÖ toplam puan ortalamaları arasında istatistiksel olarak anlamlı bir fark bulunmuştur $(p<0.05)$. (Tablo 3 ). Diğer yandan; hemşirelerin cinsiyet, medeni durum, günlük bakılan hasta sayısı, mesleki derneğe üyelik ve ekip çalışmasına yönelik bir eğitim alma durumları ile EÇTÖ toplam puan ortalaması arasında istatistiksel olarak anlamlı bir fark saptanmamıştır (Tablo 3, p>0.05).

\section{Tartışma}

Yoğun bakım ünitelerinde, hasta bakım kalitesi ve güvenliğinin artırılmasında temel etken işbirlikçi ekip çalışmasıdır. ${ }^{[21]}$ Ayrıca karar alma sürecinde etkin rol alan hemşirelerin bulunduğu ekip çalışması sayesinde yoğun bakım ünitelerinde karşılaşılan etik sorunlar da önlenebilmektedir. ${ }^{[11,16]}$ Kalisch ve Lee (2010) yaptıkları bir çalışmada; hemşirelerde ekip çalışmasının hemşirelik bakımının niteliğini ve kapsamını etkilediğini ve ekip çalışmasının geliştirilmesine yönelik yöntemlere yatırım yapılması gerektiğine işaret etmişlerdir. ${ }^{[22]} \mathrm{Bu}$ araştırma sonucuna göre hemşirelerin EÇTÖ toplam puan ortalaması $110.05 \pm 10.08$ olarak bulunmuştur. EÇTÖ'ne göre alınabilecek en yüksek puanın 140 olduğu gözönüne alındığında, çaIışmamıza katılan hemşirelerin orta düzeyde ekip çalışması tutumuna sahip olduğu söylenebilir. Benzer şekilde Çelik ve Karaca'nın (2017) hemşireler üzerinde yaptıkları bir çalışmada da; hemşirelerin EÇTÖ toplam puan ortalaması 110.67 18.78 olarak belirlenmiştir. ${ }^{[23]}$ Diğer yandan Önler ve arkadaşları (2014)'nın hemşirelik bölümü öğrencileri üzerinde yürüttükleri çalışma sonucunda ise öğrencilerin EÇTÖ toplam puan ortalaması $112.945 \pm 16.03$ olarak hesaplanmıştır. Çalışma sonucumuz bu çalışma sonuçlarıyla benzerlik göstermektedir. ${ }^{[24]}$ Yoğun bakım ünitelerindeki hastaların bakımı daha kapsamlı, daha yoğun ve çoğu zaman kritik acil girişimler gerektirmek- 
Tablo 3. Yoğun bakım hemşirelerinin bazı tanıtıcı özellikleri ile ekip çalışması tutumları ölçeği (EÇTÖ) toplam puan ortalamalarının dağılımı ( $\mathbf{n = 8 8})$

\begin{tabular}{|c|c|c|c|}
\hline Özellikler & EÇTÖ toplam puan & İstatistiksel test & $\mathbf{p}$ \\
\hline \multicolumn{4}{|l|}{ Cinsiyet } \\
\hline Kadın & $109.05 \pm 10.14$ & \multirow{2}{*}{$\mathrm{t}=-0.880^{*}$} & \multirow{2}{*}{0.384} \\
\hline Erkek & $111.68 \pm 9.94$ & & \\
\hline \multicolumn{4}{|l|}{ Eğitim durumu } \\
\hline Lisans & $109.36 \pm 10.18$ & \multirow[b]{2}{*}{$\mathrm{t}=-3.329^{*}$} & \multirow[b]{2}{*}{0.006} \\
\hline Lisansüstü & $117.00 \pm 5.63$ & & \\
\hline \multicolumn{4}{|c|}{ Çalışılan yoğun bakım kliniği } \\
\hline Beyin cerrahi & $112.00 \pm .63$ & \multirow{7}{*}{$\mathrm{F}=0.748^{* *}$} & \multirow{7}{*}{0.817} \\
\hline Kalp damar & $114.33 \pm 12.04$ & & \\
\hline Koroner & $110.90 \pm 10.52$ & & \\
\hline Genel cerrahi & $112.35 \pm 9.09$ & & \\
\hline Anestezi & $105.90 \pm 9.18$ & & \\
\hline Çocuk & $108.14 \pm 5.24$ & & \\
\hline Yenidoğan & $114.87 \pm 13.05$ & & \\
\hline \multicolumn{4}{|c|}{ Günlük bakım verilen hasta sayısı } \\
\hline $1-4$ & $110.00 \pm 8.97$ & \multirow{2}{*}{$t=-0.077^{*}$} & \multirow{2}{*}{0.939} \\
\hline $5-10$ & $110.23 \pm 13.28$ & & \\
\hline \multicolumn{4}{|c|}{ Hizmet içi eğitime katılma durumu } \\
\hline Evet & $110.06 \pm 10.77$ & \multirow{2}{*}{$\mathrm{t}=0.011^{*}$} & \multirow{2}{*}{0.991} \\
\hline Hayır & $110.04 \pm 8.29$ & & \\
\hline \multicolumn{4}{|c|}{ Mesleki bir derneğe üye olma durumu } \\
\hline Evet & $111.08 \pm 10.47$ & \multirow[b]{2}{*}{$t=1.357^{*}$} & \multirow[b]{2}{*}{0.179} \\
\hline Hayır & $108.16 \pm 9.19$ & & \\
\hline
\end{tabular}

*Bağımsız Gruplarda t Testi; **One Way Onova Testi.

tedir. Bu durum ekibin iş yoğunluğunu arttırarak, çalışanların ekip çalışmasına yönelik tutumlarını etkileyebilmektedir.

Bu çalışma sonucunda; lisansüstü hemşirelerin liderlik alt boyut ortalaması ve EÇTÖ toplam puan ortalaması arasında anlamlı bir fark bulunmuştur. Çelik ve Karaca (2017)'nın yaptıkları çalışmada, istatistiksel olarak anlamlı olmamakla birlikte lisansüstü mezunu hemşirelerin liderlik alt boyutu puan ortalaması ve EÇTÖ toplam puan ortalaması diğer hemşirelere göre yüksek bulunmuştur. ${ }^{[23]}$ Hemşirelerin eğitim düzeyi yükseldikçe liderlik ve ekip çalışması tutumlarının arttığı görülmüştür. Bu sonuçlardan eğitim seviyesinin liderlik ve ekip çalışması tutumlarını arttırmada önemli bir değişken olduğunu söylemek mümkündür.

Araştırmaya dahil olan hemşirelerin meslekte çalışma süresi arttıkça liderlik tutumunun, haftalık çalışma saati arttıkça ekip çalışması tutumlarının arttığı görülmüştür. Kalisch ve Lee (2009) tarafından yapılan bir çalışmada da hemşirelerin haftalık çalışma saati arttıkça ekip çalışması tutumlarının yükseldiği saptanmıştır. ${ }^{[25]}$ Çelik ve Karaca (2017)'nın çalışmasında ise hemşirelerin haftalık çalışma saati ile karşılıklı destek alt boyutu arasında anlamlı bir fark olduğu; meslekte çalışma yılı arttıkça durum izlemi alt boyut puan ortalamasının arttığı, fakat EÇTÖ toplam puan ortalaması ve diğer alt boyut puan ortalaması arasında bir ilişki olmadığı bulunmuştur. ${ }^{[23]}$ Dolayısıyla hemşirelerin meslekte çalışma sürelerinin liderlik alt boyutunu etkilemediği görülmektedir. Bizim çalışmamızla bu araştırma bulgusu arasındaki farkın, örnekleme dahil edilen hemşirelerin sadece yoğun bakım ünitesinde çalışıyor olmaları ve meslekte çalışma süresinin farklı olmasından kaynaklandığı düşünülmektedir.

$\mathrm{Bu}$ araştırma sonucunda; hemşirelerin cinsiyet, medeni durum, günlük bakılan hasta sayısı, mesleki derneğe üyelik ve ekip çalışmasına yönelik bir eğitim alma durumları ile EÇTÖ toplam puan ortalaması arasında istatistiksel olarak anlamIı bir fark saptanmamıştır (Tablo 3). Öğüt ve Kaya'nın (2011) yaptıkları bir çalışmada; cinsiyetin ekip çalışmasını etkilemediği bulunmuştur. ${ }^{[26]}$ Çelik ve Karaca'nın (2017) çalışmasında da hemşirelerde cinsiyetin, medeni durumun, günlük bakılan hasta sayısının ve ekip çalışmasına yönelik bir eğitim alma durumlarının ekip çalışması tutumlarını etkilemediği saptanmıştır. ${ }^{[23]}$ Çalışma sonucumuz literatür sonuçlarıyla uyumludur.

\section{Sonuç}

Hemşirelerin etkin ve verimli çalışması sağlık kurumlarının gelişiminde ve kaliteli hizmet sunumunda büyük rol oynamaktadır. Bu nedenle hemşirelerin etkinlik ve verimliliğin artırılmasında önemli bir kavram olan ekip çalışması ile ilgili 
görüş, öneri ve tutumlarının belirlenmesi önemlidir. Bu araştırma sonucunda; yoğun bakım hemşirelerinin ekip çalışması tutumlarının orta düzeyde olduğu söylenebilir. Ayrıca hemşirelerde meslekte çalışma sürelerinin liderlik tutumlarını, eğitim düzeyinin ve haftalık çalışma saatlerinin ise ekip çalışması tutumlarını etkilediği görülmüştür. Bu sonuçlar doğrultusunda;

- Hemşirelere mesleki eğitimleri sırasında ekip çalışmasının önemini belirten derslerin müfradata dahil edilmesi ve mezuniyet sonrası belli aralıklarla içi eğitim programlarının düzenlenmesi,

- Hemşirelerin belirli aralıklarla ekip çalışmasına yönelik görüşlerinin belirlenmesi,

- Ekip çalışmasını daha olumlu yönde geliştirecek ortak eğitim programlarının hazırlanması ve düzenli ekip toplantılarının yapılması,

- Araştırmanın daha geniş bir örneklemde çalışılan diğer birimler ve çalışma pozisyonu gibi farklı değişkenleri de ele alarak tekrarlanması önerilmektedir.

\section{Çıkar çatışması: Bildirilmemiştir.}

\section{Kaynaklar}

1. Manion J, Huber, DD. Team bulding and working with effective groups. In: Huber DL, editor. Leadership and nursing care management. 4th Edition. Missouri: Saunders Elsevier. 2010. p. 210-50.

2. Baykal ÜT, Türkmen EC. Hemşirelik Hizmetleri Yönetimi. Akademi Basın ve Yayıncılık: 2014; İstanbul.

3. İnce $M$, Bedük A, Aydoğan E. Örgütlerde takım çalışmasına yönelik etkin liderlik nitelikleri. Selçuk Üniversitesi Sosyal Bilimler Enstitüsü Dergisi 2004;11:423-46.

4. Jansen L. Collaborative and Interdisciplinary healthcare teams: ready or not? J Prof Nurs 2008;24:218-27.

5. McCallin A. Interdisciplinary practice-a matter of teamwork: an integrated literature review. J Clin Nurs 2001;10:419-28.

6. Ulusoy H, Tokgöz D. Hekim ve hemşirelerin ekip çalışmasına ilişkin görüşleri. Pamukkale Tıp Dergisi 2009;2:55-61.

7. Kowalski KPS. Bulding teams through comminication and partner ships. 3th ed. Missouri: Mosby; 2003.

8. Soylu F. Hemşirelerin ekip çalışmasına ilişkin görüşleri ve iş doyumları. Yayınlanmamış Yüksek Lisans Tezi. Hacettepe üniversitesi Sağlık Bilimleri Enstitüsü, 2007;Ankara.

9. Eraslan ST, Kıvanç MMJ. Türkiye'de Yoğun Bakım Hemşirelerinin Beklentileri Turk Soc Intens Care 2017;15:59-66.

10. ILO-OSH 2001 and OR- OSHA. Effective occupational safety and health management system: Integration of OHSAS 18001. 2001 [cited 4 January 2019]; Available from: https://www.nsai.ie/down-
load/certification/MD-19-02-Rev-4--OHSAS-18001-Occupational-Health-and-Safety.pdf.

11. Tel H. Yoğun bakım ünitelerinde sık karşılaşılan etik sorunlar. Cumhuriyet Hemşirelik Dergisi 2012;1:30-8.

12. Ersoy EO, Abdülkerim Ş, Öz A ve ark. Yoğun Bakım Ünitelerinde Hemşire İş Yükünün Değerlendirilmesi. Dahili ve Cerrahi Bilimler Yoğun Bakim Dergisi 2017;8:1-5.

13. Varon J, Acosta P. Approach to the intensive care unit (ICU). Handbook of critical care and intensive care medicine. 2nd ed. Springer; 2010.

14. Neuraz A, Guerin C, Payet C et al. Patient mortality is associated with staff resources and workload in the ICU: a multicenter observational study. Crit Care Med 2015;43:1587-94.

15. Conte $H$, Jirwe $M$, Scheja M, Hjelmqvist H. Get it together: Issues that facilitate collaboration in teams of learners in intensive care. Medical teacher 2016;38:491-7.

16. Yardımcı F, Başbakkal Z, Beytut D, Muslu G, Ersun A. Ekip Çalışması Tutumları Ölçeğinin geçerlilik ve güvenilirlik çalışması. Anadolu Psikiyatri Dergisi 2012;13:131-7.

17. Manser T. Teamwork and patient safety in dynamic domains of healthcare: a review of the literature. Acta Anaesthesiol Scand 2009;53:143-51.

18. Akyürek B, Özer S, Argon G, Conk Z. Hekim davranışlarının hemşire memnuniyeti ve hemşirelerin işine devam etme durumu üzerine etkisi. Ege Tıp Dergisi 2005;44:167-72.

19. Tambağ H, Mansuroğlu S, Yıldırım G. Determination of the spirutual support perception of intensive care unit nurses: a pilot study. J Contemp Med 2018;8:159-64.

20. Baker DP, Krokos KJ, Amodeo AM. TeamSTEPPS teamwork. Attitudes questionnaire manual. In: Rockville MD, editör. Agency for healthcare research and quality. 2008. [Included in the TeamSTEPPS Instructors Guide.]

21. Bjurling-Sjöberg P, Wadensten B, Pöder U, Jansson I, Nordgren L. Balancing intertwined responsibilities: a grounded theory study of teamwork in everyday intensive care unit practice. Journal of Interprofessional Care 2017;31:233-44.

22. Kalisch BJ, Lee KH. The impact of teamwork on missed nursing care. Nursing Outlook 2010;58:233-41.

23. Çelik A, Karaca A. Hemşirelerde Ekip Çalışması ve Motivasyon Arasındaki İlişkinin ve Etkileyen Faktörlerin Değerlendirilmesi. Hemşirelikte Eğitim ve Araştırma Dergisi 2017;14:254-63.

24. Önler E, YıldızT, Süzen ER ve ark. Hemşirelik Bölümü Öğrencilerinin Ekip Çalışması Tutumları İle Duygusal Zeka Düzeyleri Arasındaki İlişkinin Değerlendirilmesi. IAAOJ, HealthSciences,2014;2:19-29.

25. Kalisch BJ, Lee H. Nursing teamwork, staff characteristics, work schedules, and staffing. Health Care Management Review 2009;34:323-33.

26. Öğüt A, Kaya DŞ. Sağlık kurumlarında ekip çalışması. Selçuk Üniversitesi Kadınhanı Faik İçil Meslek Yüksekokulu Sosyal ve Teknik Araştırmalar Dergisi 2011;1:87-95. 